\title{
Sistem Penjadwalan Bel Sekolah Otomatis Berbasis RTC Menggunakan Mikrokontroler
}

\author{
Randi Rian Putra', Hamdani², Soly Aryza², Nelly Astri Manik ${ }^{1, "}$ \\ ${ }^{1}$ Fakultas Sains dan Teknologi, Program Studi Sistem Komputer, Universitas Pembangunan Panca Budi, Medan, Indonesia \\ ${ }^{2}$ Fakultas Sains dan Teknologi, Program Studi Teknik Elektro, Universitas Pembangunan Panca Budi, Medan, Indonesia \\ Email: ${ }^{1}$ randirian@dosen.pancabudi.ac.id, ${ }^{2}$ hamdani@dosen.pancabudi.ac.id, ${ }^{3}$ sollyaryzalubis@gmail.com, \\ 4," nellyastri51@gmail.com, \\ Email Penulis Korespondensi: nellyastri51@gmail.com
}

\begin{abstract}
Abstrak-Teknologi bel sekolah saat ini telah berubah menjadi bel sekolah berbasis listrik. Bel sekolah berbasis listrik merupakan teknologi pengganti lonceng sekolah yang dilakukan dengan memukulnya hingga menjadi bel sekolah berbasis tombol untuk membunyikannya. Tujuan penelitian ini adalah membangun sistem penjadwalan bel sekolah otomatis yang diintegrasikan dengan mikrokontroler ATMega328P sebagai pemproses data, RTC (Real Time Clock) sebagai pewaktu, Bluetooth sebagai penghubung ke smartphone untuk mengganti jadwal mata pelajaran, dan PAM8403 Sebagai Aplifier penguat suara yang terhubung dengan DFPlayer dan Speaker. Rangkaian sistem dibangun menggunakan modul mikrokontroler ATMega328P, RTC DS3231 (Real Time Clock), Bluetooth HC05, DFPlayer, PAM8403. Penelitian ini menghasilkan sistem penjadwalan bel sekolah otomatis berbasis RTC dengan menggunakan Mikrokontroler ATMega328P
\end{abstract}

Kata Kunci: Aplikasi, Bel Sekolah, Bluetooth, Mikrokontroler, Real Time Clock

\begin{abstract}
Today's school bell technology has been transformed into an electricity-based school bell. An electric school bell is a technology that replaces school bells by hitting them to become a button based school bell to ring it. The purpose of this study is to build an automatic school bell scheduling system that is integrated with the ATMega328P microcontroller as a data processor, RTC (Real Time Clock) as a timer, Bluetooth as a liaison to smartphones to change subject schedules, and PAM8403 as a sound amplifier applicator that is connected to DFPlayer and Speaker. The system circuit is built using the microcontroller module ATMega328P, RTC DS3231 (Real Time Clock), Bluetooth HC05, DFPlayer, PAM8403. This research resulted in an automatic school bell scheduling system based on RTC using a microcontroller ATMega328P.
\end{abstract}

Keywords: Application, School Bell, Bluetooth, Microcontroller, Real Time Clock

\section{PENDAHULUAN}

Bel merupakan suatu alat yang dapat mengeluarkan bunyi dan mempunyai fungsi sebagai kode, alat pengingat dan alat komunikasi. Seiring dengan perkembangan zaman, bel yang masih sederhana itu dirubah menjadi bel listrik manual[1]. Umumnya pada sebagian besar sekolah pengoperasian bel sekolah ini dilakukan secara manual, yaitu ada guru piket atau petugas sekolah yang harus selalu siap untuk membunyikan bel sekolah sesuai dengan jam-jam yang telah ditentukan dengan cara melihat waktu pada jam dinding dan menekan tombol bel[2]. Seiring dengan kemajuan zaman sehingga hampir semuanya yang manual dibuat menjadi terkomputerisasi.

Dengan adanya sistem komputerisasi ini membuat pengguna lebih mudah dalam menyelesaikan segala permasalahannya. Dalam kegiatan belajar mengajar disekolah pihak penjaga sekolah/guru piket disibukkan dengan aktifitas membunyikan bel di sekolah saat jam masuk sekolah, ganti pelajaran, istirahat serta pulang sekolah yang mungkin setiap hari lebih dari lima kali. Tetapi petugas seringsekali lupa membunyikan bel sekolah pada saat yang tepat, Dari kelalaian tersebut menyebabkan tersitanya waktu pelajaran yang menyebabkan efektifitas kegiatan belajar mengajar menjadi berkurang[3].

Dari permasalahan inilah yang melatar belakangi penulis untuk membangun suatu sistem penjadwalan bel sekolah otomatis berbasis RTC (Real Time Clock) dengan Mikrokontroler ATmega32P yang dimanfaatkan untuk menyimpan data waktu penjadwalan memulai dan mengakhiri proses belajar mengajar maupun istirahat belajar secara real time. Maka bel sekolah akan aktif sesuai dengan inputan jadwal yang telah di program.

Ada beberapa penelitian terdahulu yang menggunakan mikrokontroler berbasis Rtc dalam perancangan bel sekolah otomatis. Salah satunya adalah penelitian yang berjudul "perancangan bel sekolah otomatis menggunakan mikrokontroler avr atmega 328 dan real time clock ds3231" Penelitian ini membahas tentang perancangan dan pembuatan bel otomatis berbasis real time clock dengan mikrokontroler[2].

RTC merupakan sebuah chip yang berfungsi untuk menghitung waktu yang dimulai dari hitungan detik, menit, jam, hari, bulan dan tahun[4]. Sedangkan Mikrokontroler (bahasa Inggris: microcontroller)merupakan sistem mikroprosesor lengkap yang terkandung di dalam sebuah chip[5]

\section{METODE PENELITIAN}

\subsection{Tahapan Penelitian}

Ada pun tahapan penelitian yang dilakukan oleh penulis dalam memperoleh data-data yang digunakan untuk kebutuhan penelitian adalah sebagai berikut : 


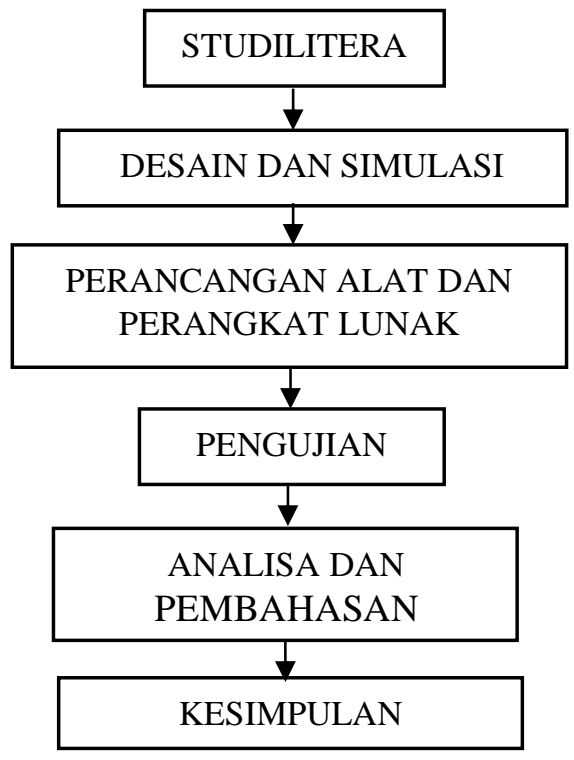

Gambar 1. Tahapan Penelitian

1. Studi literatur, yaitu melakukan tinjauan kepustakaan yang terkait dengan masalah yang dibahas.

2. Desain dan simulasi, yaitu membuat desain prototype yang akan dibuat dengan melakukan simulasi dengan menggunakan software Proteus untuk mendapatkan gambaran prototype yang akan dibuat.

3. Perancangan \& Realisasi, yaitu membuat perangkat keras seperti perancangan rangkaian minimum sistem Mikrokontroler ATMega328, RTC DS3231, LCD, Bluetooth HC05, DFPlayer, PAM8403 dan Speaker.

4. Pengujian sistem, diharapkan dalam tahap ini sistem berjalan dengan baik, baik pada rangkaian maupun programnya.

5. Analisa data, yaitu mengambil data yang didapatkan pada saat pengujian. Pada tahap ini diharapkan dapat ditemukan gagasan baru untuk pengambilan kesimpulan.

6. Penarikan kesimpulan, yaitu mengambil kesimpulan dari penelitian yang telah dilakukan.

\subsection{Metode Pengumpulan Data}

Pada penelitian ini, menggunakan metode pengamatan dan studi kasus yang dilakukan dilingkungan sekolah. Dari hasil pengamatan yang telah dilakukan, terdapat suatu permasalahan yang muncul dilapangan, yaitu selama ini cara yang digunakan untuk membunyikan bel sekolah masih menggunakan tenaga manusia, cara ini masih dirasa kurang efisien dan kurang efektif. Dari permasalahan tersebut, kemudian digunakan sebagai bahan kajian dan analisa untuk mencegah masalah yang sama timbul dikemudian hari[6]

Adapun Teknik pengumpulan data yang dibutuhkan penelitian ini adalah:

a) Pengamatan atau observasi, yaitu melakukan pengamatan langsung terhadap fenomena yang diamati dan melakukan pencatatan sistematis terhadap gejala-gejala yang ditemukan.

b) Wawancara, yaitu melakukan pembicaraan langsung (tanya jawab) terhadap informan yang dianggap mengetahui pokok permasalahan penelitian ini.

c) Studi kepustakaan, yaitu mengumpulkan datadata dan keterangan dengan cara membaca berbagai buku literatur maupun artikel yang berhubungan dengan permasalahan penelitian untuk mendapatkan landasan serta pengertian secara teoritis yang mendalam[2]

\subsection{Analisis Sistem Yang Sedang Berjalan}

Adapun sistem yang sedang berjalan yang sering di jumpai oleh penulis adalah bel atau lonceng sekolah yang merupakan alat bantu untuk memberikan instruksi kepada seluruh murid dalam melaksanakan suatu kegiatan tertentu. Yang pada umumnya sekolah masih menggunakan lonceng yang terbuat dari bahan besi yang kemudian dipukul dengan tekhnik tertentu agar menghasilkan suara untuk menyampaikan suatu informasi kepada murid, seperti 3x pukulan menandakan berbaris dihalaman dan sebagainya.

\subsection{Rancangan Penelitian}

Perancangan merupakan proses tahapan yang fokusnya pada desain sistem yang hendak dibangun meliputi perancangan data flow diagram, perancangan basis data, tampilan atau desain I/O dan perangkat[7] 
JURNAL MEDIA INFORMATIKA BUDIDARMA

Volume 4, Nomor 2, April 2020, Page 386-395

ISSN 2614-5278 (media cetak), ISSN 2548-8368 (media online)

Available Online at https://ejurnal.stmik-budidarma.ac.id/index.php/mib DOI 10.30865/mib.v4i2.1957

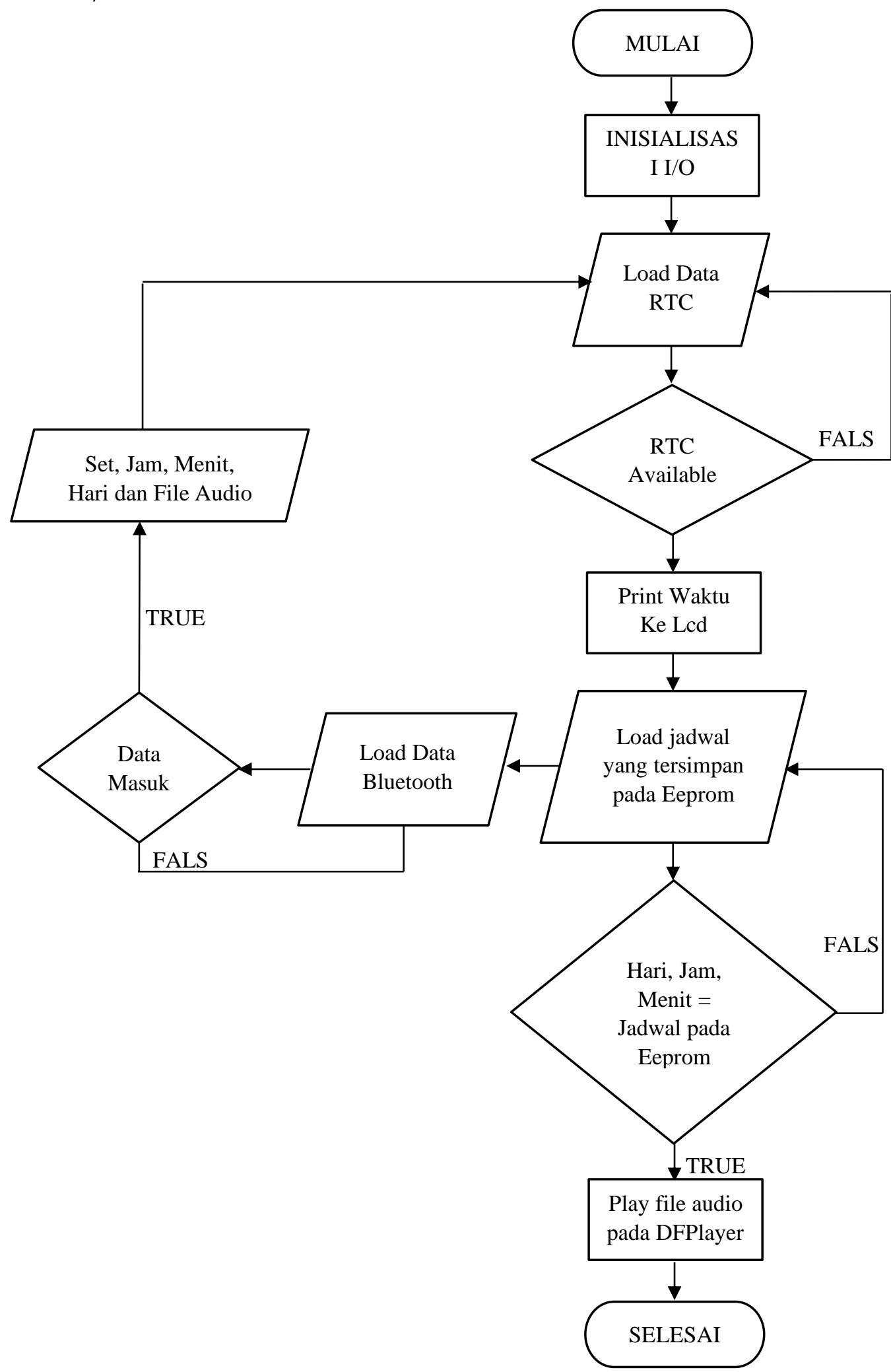

Gambar 2. Flowchart Program

Berdasarkan Flowchart pada gambar 2 dapat kita ketahui bagaimana proses kerja dari alat bel otomatis, yaitu alat akan mengambil data waktu, tanggal, dan hari dari RTC, kemudian data waktu akan ditampilkan pada LCD I2C. Data waktu, tanggal dan hari akan di bandingkan dengan data yang tersimpan pada EEPROM. Kemudian memainkan file mp3 yang ada pada DFPlayer. Untuk mengubah data waktu, tanggal, hari dan jadwal dapat dilakukan dengan menghubungkan alat dengan aplikasi menggunakan koneksi Bluetooth.

\subsection{Rangkaian Perancangan Alat (Hardware)}

Randi Rian Putra, Copyright (C2020, MIB, Page 388 


\section{JURNAL MEDIA INFORMATIKA BUDIDARMA}

Volume 4, Nomor 2, April 2020, Page 386-395

ISSN 2614-5278 (media cetak), ISSN 2548-8368 (media online)

Available Online at https://ejurnal.stmik-budidarma.ac.id/index.php/mib DOI 10.30865/mib.v4i2.1957

Perancangan hardware merupakan suatu tahap yang sangat penting dalam pembuatan suatu alat, sebab dengan menganalisa komponen yang digunakan maka alat yang akan dibuat dapat bekerja seperti yang diharapkan. Untuk mendapatkan hasil yang optimal, terlebih dahulu membuat rancangan yang baik. Yaitu dengan memperhatikan sifat dan karakteristik dari tiap-tiap komponen yang digunakan sehingga dapat menghindari kerusakan pada komponen yang digunakan dan mempermudah dalam pengerjaannya

\subsubsection{Rangkaian Mikrokontroler}

Sebuah pengembangan lebih lanjut mengenai mikroprosesor adalah mikrokontroler. Bila dalam penggunaannya, mikroptrosesor membutuhkan RAM (Random Akses Memory dan ROM (Read Only Memory) untuk membuat suatu alat yang sederhana. Akan tetapi dalam sebuah chip mikrokontroler, piranti - piranti tersebut telah terintegrasi cukup lengkap di dalamnya, bahkan sekarang mikrokontroler ada yang memiliki piranti - piranti tambahan lain yang telah terintegrasi didalamnya, seperti ADC (Analog Digital Converter), RTC (Real Time Clock), dan lain - lain[8]. Penggunaan mikrokontroler memberikan tingkat fleksibilitas yang lebih baik karena kemampuannya untuk dikoneksikan dengan perangkat lain. Di samping itu, suatu sistem harus informatif karena mampu ditampilkan dalam bentuk visual maupun audio ataupun gabungan dari keduanya[9]

Rangkaian mikrokontroler ATmega 328:

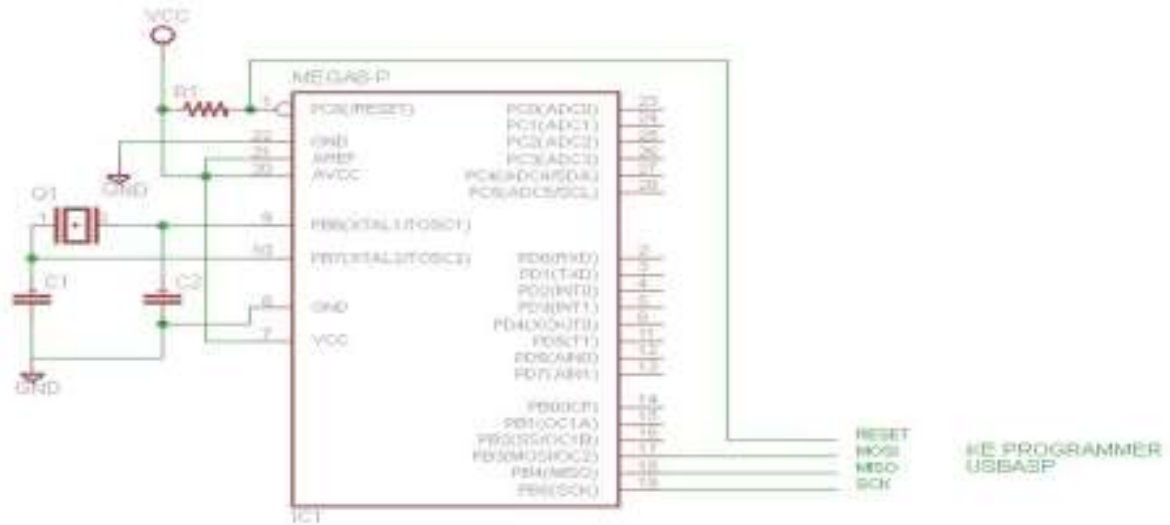

Gambar 3. Skema Rangkaian Mikrokontroler ATMega328

\subsubsection{Rangkaian Bluetooth dengan Mikrokontroler ATMega328}

Pada rangkaian ini Bluetooth berfungsi untuk mengubah ataupun mengatur jadwal mata pelajaran yang langsung terhubung ke smartphone. Bluetooth yang digunakan adalah Bluetooth HC-05 yang bekerja sebagai media komunikasi antara mikrokontroler ATmega328 dengan smartphone android

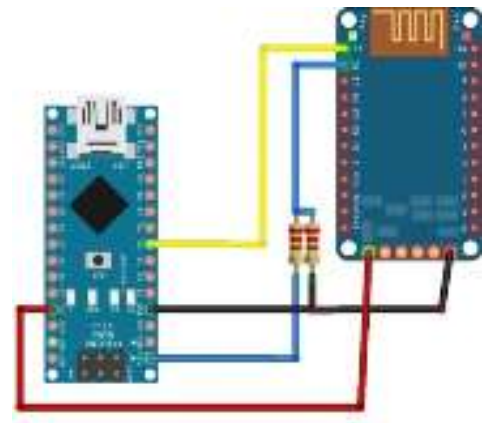

Gambar 4. Rangkaian ATmega328 dengan Bluetooth HC-05

Keterangan:

1. Kaki TX pada Bluetooth dihubungkan dengan pin RX pada ATmega328.

2. Kaki RX pada Bluetooth dihubungkan dengan pin TX pada ATmega328.

3. Kaki VCC pada Bluetooth dihubungkan dengan pin VCC pada ATmega328.

4. Kaki GND pada Bluetooth dihubungkan dengan pin GND pada ATmega328.

\subsubsection{Rangkaian Real Time Clock (RTC)}

Real Time Clock atau sering disebut juga RTC merupakan salah satu komponen elektronika aktif yang dapat menyimpan data tanggal dan waktu di dalamnya[10]. Bentuk komunikasi data dari RTC adalah I2C yang hanya menggunakan 2 jalur komunikasi yaitu SDA dan SCL. Pada rangkain ini Pin SDA dihubungkan pada pin A4 dan SCL pada pin A5. 


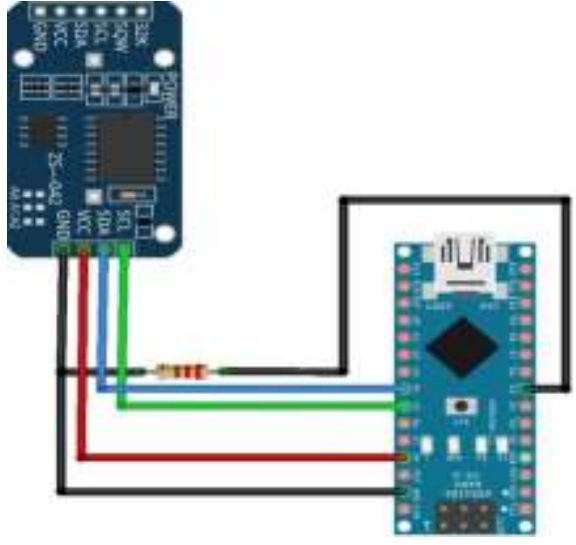

Gambar 5. Rangkaian RTC

\subsubsection{Rangkaian LCD I2C}

Pada perancangan ini penggunaan LCD I2C adalah untuk menampilkan status dari alat dan jam. Pin yang digunakan LCD I2C pada ATmega328 adalah pin SDA pada Bluetooth dihubungkan ke pin A6 pada ATmega328 dan pin SCL pada Bluetooth dihubungkan ke pin A7 pada ATmega328. Rangkaian ATmega328 dengan LCD I2C dapat dilihat pada gambar berikut ini

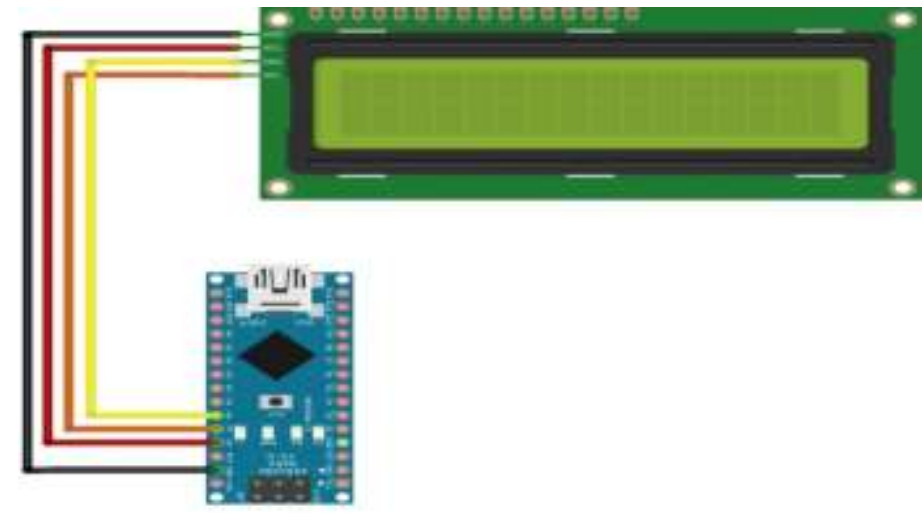

Gambar 6. Rangkaian LCD I2C

\subsubsection{Rangkaian DFPlayer dan Amplifier}

Mesin bel dapat memainkan file suara atau audio dalam format .mp3 dan .wav melalui komponen DFPlayer ini. Pada komponen DFPlayer ini terdapat sebuah mini SDCard yang akan diisi file-file suara atau audio bel sekolah seperti suara untuk menyampaikan jam masuk kelas, pergantian jam pelajaran, upacara dan file-file pendukung lainnya[11]

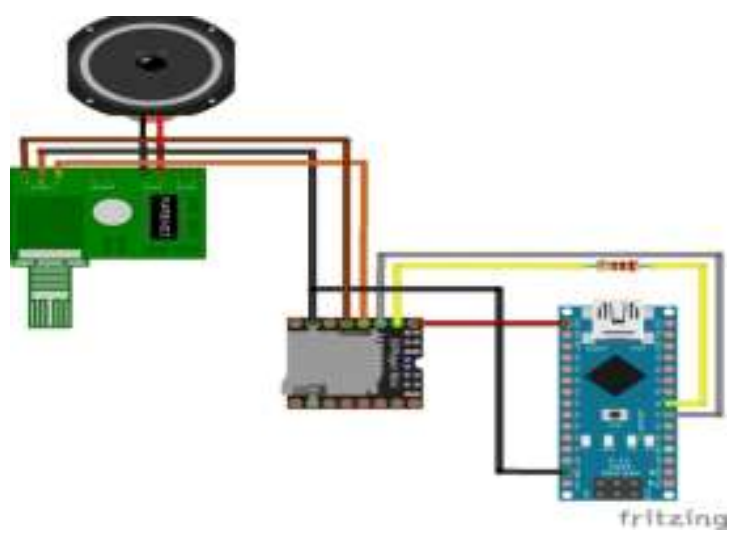

Gambar 7. Rangkaian DFPlayer dan Amplifier

\subsubsection{Rangkain Secara Keseluruhan}

Berikut adalah rangkaian secara keseluruhan pada sistem penjadwalan bel sekolah otomatis menggunakan suara berbasis RTC dengan menggunakan Mikrokontroler ATMega328P 


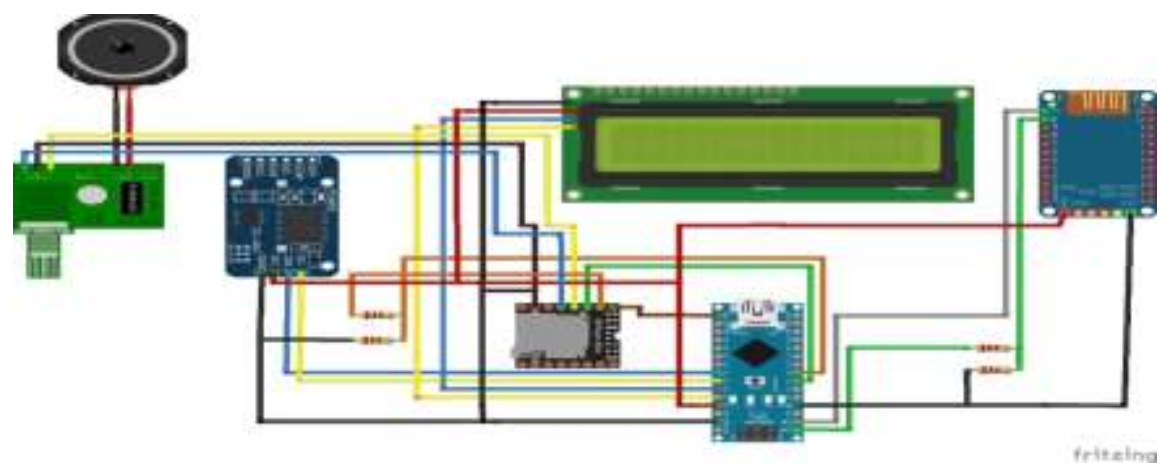

Gambar 8. Rangkaian Sistem Alat Bel Otomatis

Gambar diatas merupakan rangkaian keseluruhan sistem penjadwalan bel sekolah otomatis dimana Catu daya mensuplai energi listrik untuk menghidupkan dan mematikan sistem ke Mikrokontroler ATMega328P. Mikrokontroler ATMega328P menerima input data mentah dan mengirimkannya ke Modul RTC untuk diproses. Modul RTC melakukan pemrosesan data dan menghasilkan instruksi-instruksi yang kemudian dikirim kembali ke Mikrokontroler. Mikrokontroler mengirimkan output ke LCD berupa Jam / Menit Jadwal mata pelajaran. Mikrokontroler mengirimkan data ke DFPlayer untuk membaca jadwal mata pelajaran. DFPlayer membaca jadwal dan mengirimkan file audio ke PAM8403. Setelah file audio dibaca oleh PAM8403 selanjutnya akan mengirimkan output berupa suara ke speker pertanda perubahan jadwal mata pelajaran. Untuk mengubah jadwal mata pelajaran yang berlangsung maka Mikrokontroler mengirim file ke Bluetooth HC05 yang langsung terhubung dengan smartphone.

\subsection{Perancangan PCB (Printed Circuit Board)}

Printed Circuit Board (PCB) adalah sebuah papan rangkaian yang terbuat dari bahan ebonit (Pertinax) atau fiber glass dimana salah satu sisi permukaanya dilapisi dengan tembaga tipis. Jenis ini umumnya disebut single side karena hanya memiliki satu permukaan yang berlapiskan tembaga. Sedangkan PCB yang ke dua sisinya digunakan untuk pembuatan rangkaian yang bersifat kompleks dan rumit, sehingga ke dua bagian sisinya dapat difungsikan sebagai jalur dan tempat komponen-komponen.

Perancangan PCB pada pembuatan alat bel otomatis ini menggunakan software ISIS \& ARES Proteus 8.0. Proteus adalah sebuah software berbasis windows yang dapat digunakan untuk mendesain PCB yang juga dilengkapi dengan simulasi pspice pada level skematik sebelum rangkaian skematik di cetak pada PCB.

Dengan perancangan yang tepat akan didapatkan layout PCB yang tersusun rapi dan mudah digunakan. Lebar dan jarak antara jalur juga harus diperhitungkan agar tidak terjadi kesalahan atau hubungan singkat akibat jalur yang terlalu rapat dan sempit.

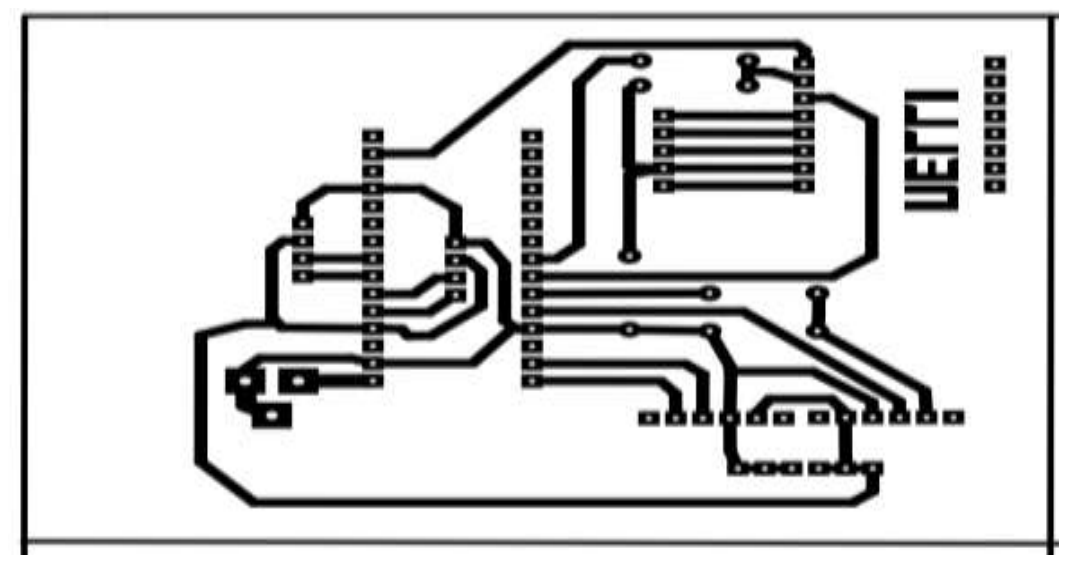

Gambar 9. Layout PCB Shield Mikrokontroler

\subsection{Perancangan Perangkat Lunak (Software)}

Perancangan perangkat lunak dibuat melalui software IDE (Integrated Developer Environment) Arduino itu sendiri dengan menggunakan bahasa $C$. Pada sistem ini, program dibuat agar dapat menerima input dari Mikrokontroler dan memberikan output ke speaker.

Perangkat keras sebagai pengendali tidak dapat bekerja jika tidak disertai dengan perangkat lunak sebagai pengatur fungsi kerja keseluruhan sistem. Perangkat bertugas untuk menentukan langkah-langkah yang harus dilakukan mikrokontroler baik input maupun output pada keseluruhan sistem, sehingga nantinya dapat ditentukan arah kendali atau proses dari sistem yang dibuat. Mikrokontroler merupakan pengendali utama dari 
JURNAL MEDIA INFORMATIKA BUDIDARMA

Volume 4, Nomor 2, April 2020, Page 386-395

ISSN 2614-5278 (media cetak), ISSN 2548-8368 (media online)

Available Online at https://ejurnal.stmik-budidarma.ac.id/index.php/mib DOI 10.30865/mib.v4i2.1957

keseluruhan sistem. Mikrokontroler tidak akan bisa berfungsi jika didalamnya tidak di masukkan sebuah program (software).

\section{HASIL DAN PEMBAHASAN}

\subsection{Pengujian Sistem}

Pengujian sistem yang dilakukan penulis merupakan pengujian terhadap perangkat keras dan perangkat lunak dari aplikasi bel sekolah otomatis dengan menghubungkan alat bel dengan smartphone melalui Bluetooth, serta program pada arduino secara keseluruhan yang telah selesai dibuat.

\subsection{Pengujian dan Evaluasi Aplikasi Android Bel Sekolah}

Android adalah operating system atau OS berbasis linux yang diperuntukan khusus untuk mobile device seperti smartphone atau PC table, persis seperti symbian yang digunakan oleh Nokia dan Blackberry OS, jelasnya seperti Microsoft windows yang sangat dikenal baik oleh para pengguna komputer dan laptop, jika kita analogikan, android adalah windows nya sedangkan smartphone atau handphone atau tablet adalah unit komputernya[12].

Pengujian aplikasi Android bel sekolah ini dilakukan untuk mengetahui apakah program yang dibuat pada software android dapat terinstal pada smartphone dan dapat berjalan dengan baik. Dimana software ini buat dengan menggunakan App Inventor yang merupakan aplikasi web sumber terbuka yang awalnya dikembangkan oleh Google, dan saat ini dikelola oleh Massachusetts Institute Of Technology (MIT) yang digunakan untuk memprogram komputer untuk menciptakan aplikasi perangkat lunak bagi sistem Android. Dimana pada penelitian ini penulis menggunakan MIT App Invertor dari situs http://ai2.appinventor.mit.edu/.

Lankah- lankah pembuatan aplikasi android:

a. Menu Pengaturan

Dimana menu ini berfungsi untuk memasukkan jadwal mata pelajaran yang akan di laksanakan pada setiap harinya. Berikut ini adalah tampilan dalam menu pengaturan :

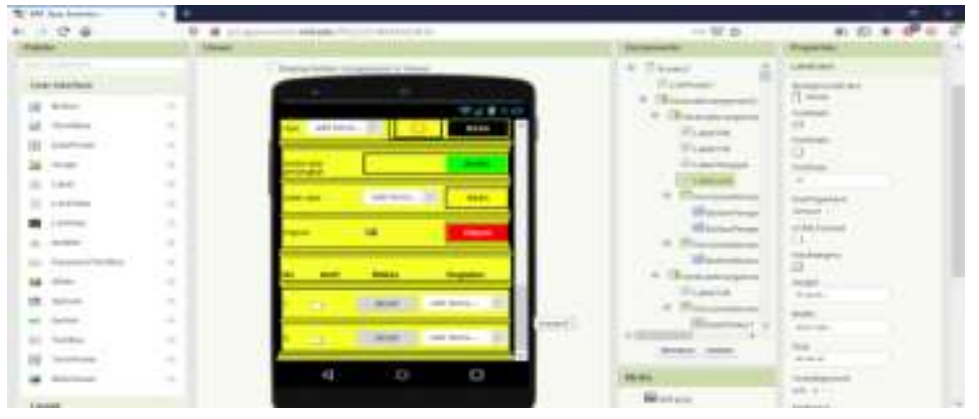

Gambar 10. Tampilan Menu Pengaturan

Berikut adalah tampilan program untuk menampilkan menu Pengaturan :

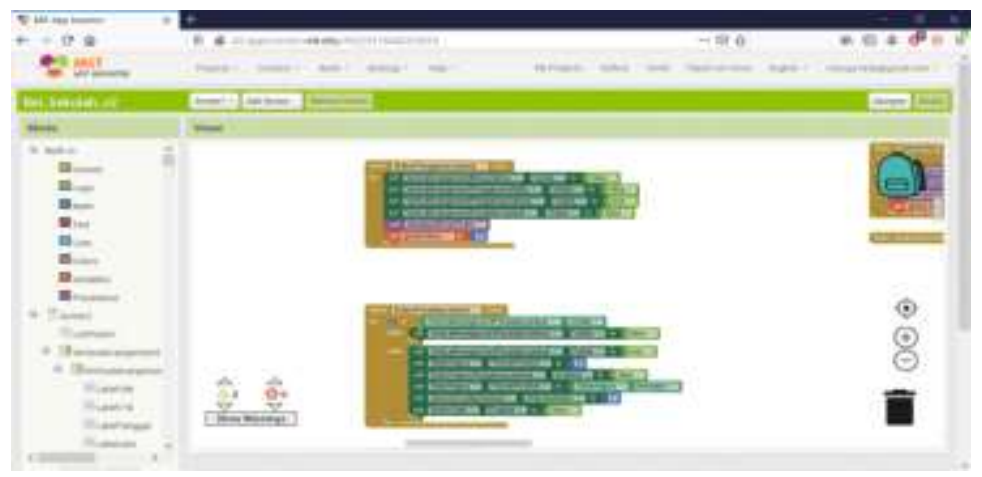

Gambar 11. Program Fungsi Atur Jadwal

b. Menu Waktu

Menu ini berfungsi untuk menyesuaikan waktu pada RTC dengan waktu pada Smartphone. Berikut adalah tampilan dalam pada menu pengaturan waktu : 
ISSN 2614-5278 (media cetak), ISSN 2548-8368 (media online)

Available Online at https://ejurnal.stmik-budidarma.ac.id/index.php/mib DOI 10.30865/mib.v4i2.1957

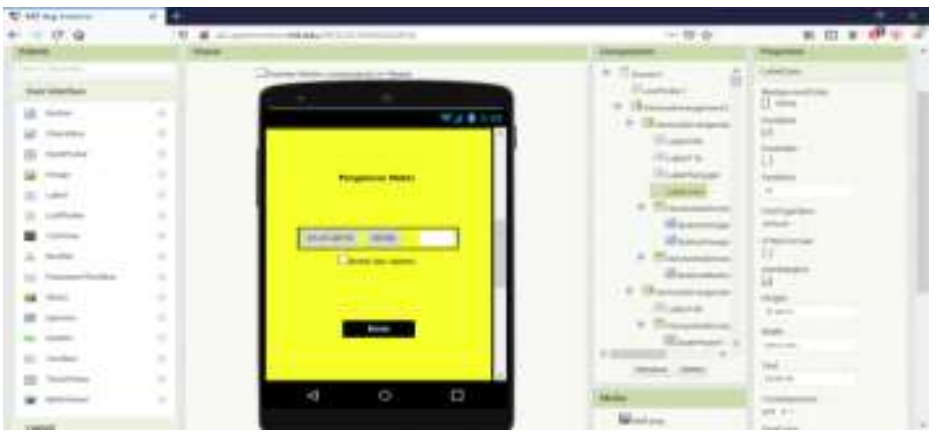

Gambar 12. Tampilan Menu Waktu

Berikut adalah program dalam menampilkan menu fungsi atur Waktu

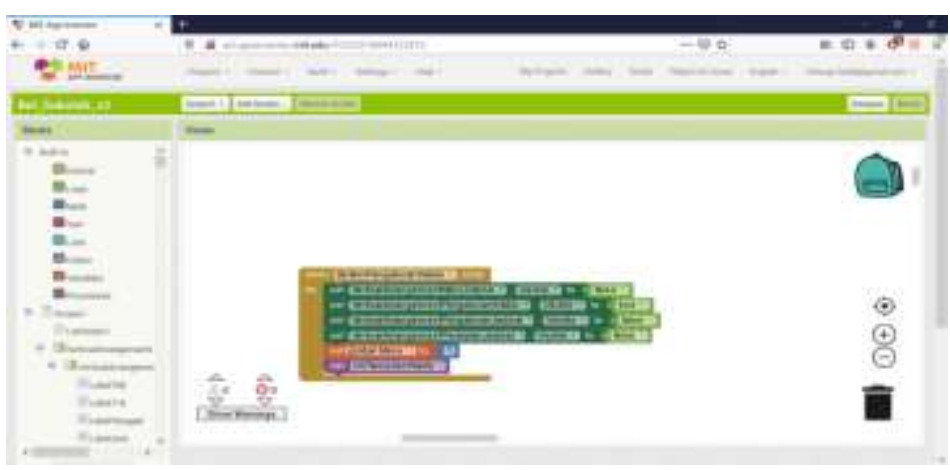

Gambar 13. Program Menu Fungsi Atur Waktu

c. Menu Bluetooth

Menu ini berfungsi untuk menghubungkan Eeprom dengan smartphone dengan menggunakan Bluetooth. Berikut ini adalah program dalam menghubungkan alat dengan smartphone dengan menggunakan Bluetooth.

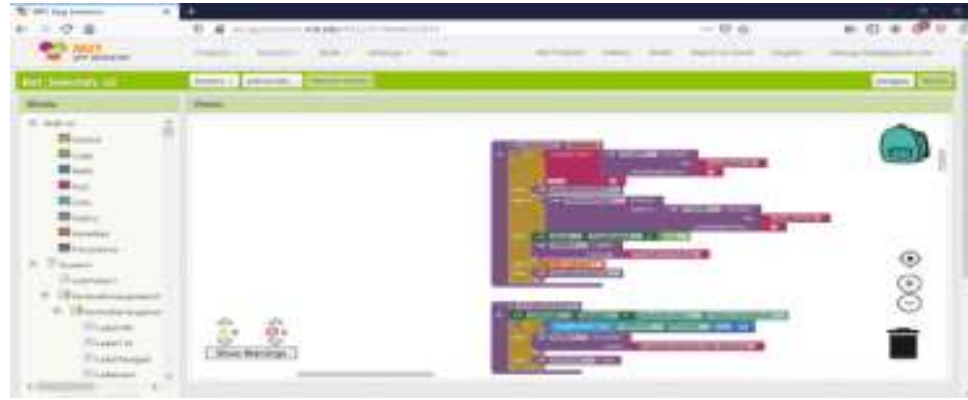

Gambar 14. Program Menu Bluetooth

d. Tampilan Awal Aplikasi Android

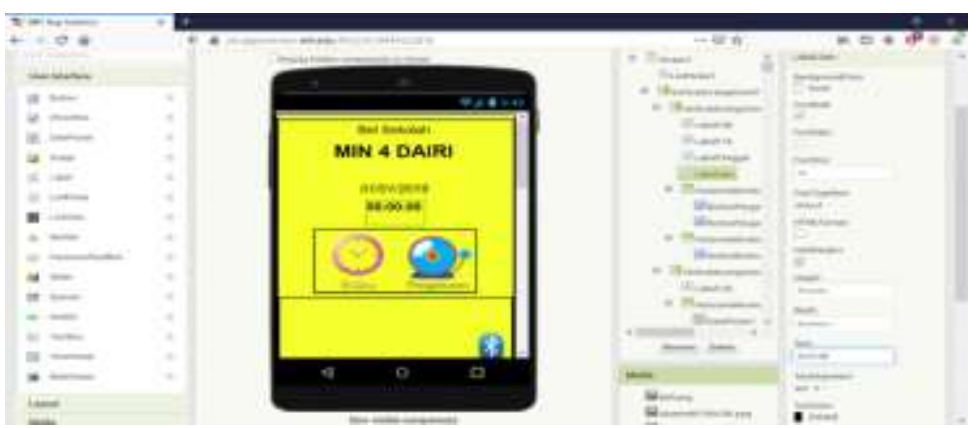

Gambar 15. Tampilan Awal Aplikasi Adroid

\subsection{Pengujian dan Hasil Alat Secara Keseluruhan}

Pengujian dilakukan dengan mengoperasikan alat kontrol bel sekolah ini secara langsung sesuai dengan objek penelitian yaitu jadwal sekolah MIN 4 Dairi, adapun jadwal mata pelajaran sekolah tersebut ada pada lampiran II pada skripsi ini. 
JURNAL MEDIA INFORMATIKA BUDIDARMA

Volume 4, Nomor 2, April 2020, Page 386-395

ISSN 2614-5278 (media cetak), ISSN 2548-8368 (media online)

Available Online at https://ejurnal.stmik-budidarma.ac.id/index.php/mib DOI 10.30865/mib.v4i2.1957

Setelah melakukan perancangan sistem kontrol bel sekolah otomatis menggunakan suara berbasis RTC dengan Mikrokontroler ATMega328P dilanjutkan dengan pengujian dan perbaikan sehingga diperoleh realisasi perangkat keras secara keseluruhan seperti pada gambar di bawah ini :

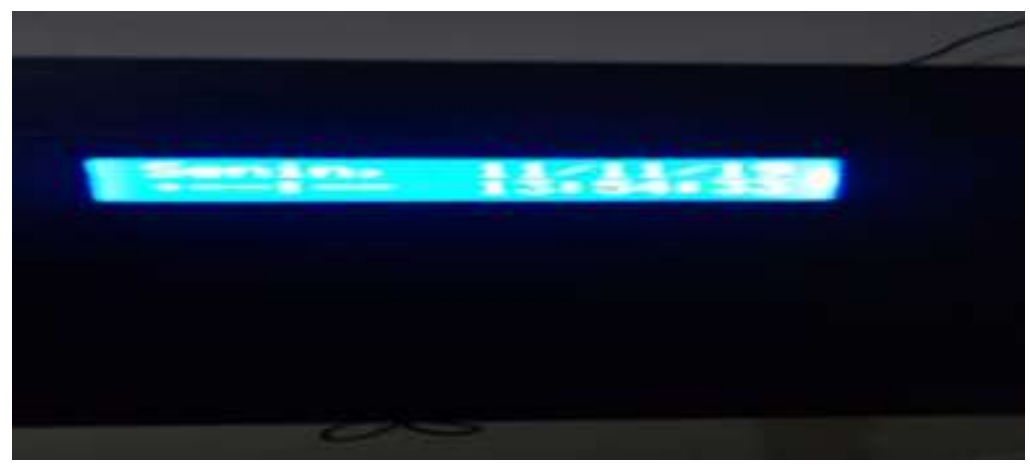

Gambar 16. Tampilan luar perangkat keras bel sekolah

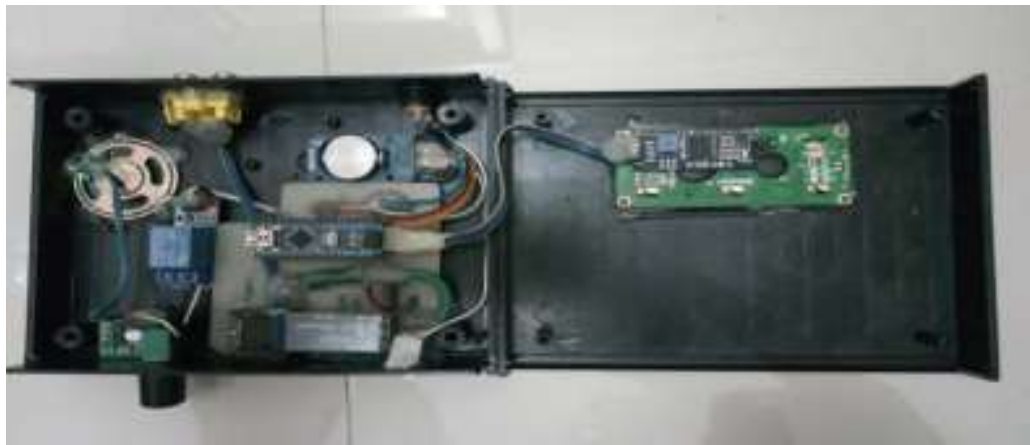

Gambar 17. Tampilan dalam perangkat keras bel sekolah

Adapun table dari sistem kesesuaian jadwal pengujian adalah sebagai berikut:

Tabel 1. Tabel Pengujian Sistem Kesesuaian Jadwal

\begin{tabular}{cccl}
\hline \multirow{2}{*}{ No } & \multirow{2}{*}{ Waktu } & \multirow{2}{*}{ Kegiatan } & \multicolumn{2}{c}{ Hasil Pengujian } \\
& & Sesuai & Tidak Sesuai \\
\hline 1. & 07.30 & Upacara & Sesuai \\
2. & 08.05 & Jam Pelajaran 1 & Sesuai \\
3. & 08.40 & Jam Pelajaran 2 & Sesuai \\
4. & 09.15 & Istirahat & Sesuai \\
5. & 09.25 & Selesai Istirahat & Sesuai \\
6. & 09.25 & Jam Pelajaran 3 & Sesuai \\
7. & 10.00 & Jam Pelajaran 4 & Sesuai \\
8. & 10.35 & Jam Pelajaran 5 & Sesuai \\
9. & 11.10 & Istirahat & Sesuai \\
10. & 11.20 & Selesai Isirahat & Sesuai \\
12. & 11.55 & Jam Pelajaran 7 & Sesuai \\
13. & 12.30 & Pulang & Sesuai \\
\hline
\end{tabular}

\section{KESIMPULAN}

Dari hasil pengujian dan analisa yang telah dilakukan pada perancangan bel sekolah otomatis ini, dapat diambil sebagai kesimpulan sebagai berikut :

1. Perancangan sistem penjadwalan bel sekolah otomatis berbasis RTC dengan Mikrokontroler ATmega328P telah berhasil dibuat dan mampu bekerja dengan baik. Hal ini terlihat dari hasil pengujian alat yang telah dilakukan oleh LCD, yaitu mampu menampilkan jadwal mata pelajaran yang akan berlangsung dengan benar. Sedangkan speaker dapat mengeluarkan suara yang sesuai dengan perintah yang ditampilkan oleh LCD.

2. Alat perancangan bel otomatis telah mampu bekerja dengan baik ketika diuji coba pada Madrasah Ibtidaiyah Negeri (MIN) 4 Dairi. Dimana ketika LCD menampilakan Pukul 07:15 maka speaker akan mengeluarkan suara pertanda bahwa siswa akan masuk ke ruangan belajar, dan pertanda proses belajar mengajar akan 


\section{JURNAL MEDIA INFORMATIKA BUDIDARMA}

Volume 4, Nomor 2, April 2020, Page 386-395

ISSN 2614-5278 (media cetak), ISSN 2548-8368 (media online)

Available Online at https://ejurnal.stmik-budidarma.ac.id/index.php/mib

DOI 10.30865/mib.v4i2.1957

segera dimulai. Hal ini cukup membantu kepada pihak sekolah, terutama guru piket maupun tata usaha di sekolah tersebut karena tidak repot untuk menekan bel pada saat pergantian jadwal pelajaran. Dan pelaksanaan proses belajar mengajar menjadi lebih efisien karena pertanda pergantian jadwal pelajaran akan sesuai dengan perintah yang telah tersimpan pada RTC.

\section{REFERENCES}

[1] A. L. Affandy, "Rancang Bangun Bel Sekolah Otomatis Berbasis Personal Computer ( PC )," vol. 8, no. 3, pp. 194 206, 2017.

[2] D. Kusumawati and B. A. Wiryanto, "PERANCANGAN BEL SEKOLAH OTOMATIS MENGGUNAKAN MIKROKONTROLER AVR ATMEGA 328 DAN REAL TIME CLOCK DS3231,” vol. 4, no. 1, pp. 13-22, 2018.

[3] Q. dkk Hidayah, "Rancang bangun bel otomatis berbasis rtc ds3231 menggunakan arduino uno r3 sebagai tanda pergantian jadwal," vol. 6, no. 1, pp. 1-8.

[4] T. Elektronika, P. Studi, T. Elektro, and F. Jakarta, "PENDISTRIBUSIAN AIR BERBASIS MIKROKONTROLER," vol. XX, no. 2, pp. 85-91, 2018.

[5] D. Satria and Y. Yanti, "Design of Arduino Uno Based School Bell Scheduling System with Web-Based Interface Using Ethernet Web Server," Serambi Eng., vol. II, no. 3, pp. 141-147, 2017.

[6] Sarmidi; Bardisila Bhui, "Jurnal manajemen dan teknik informatika," Ranc. Bangun Sist. Inf. Pengolah. Bank Sampah Puspasari Kec. Purbaratu Kota Tasikmalaya, vol. 02, no. 01, pp. 181-190, 2018.

[7] M. Subianto, "Sistem Bel Otomatis Terprogram Berbasis Raspberry Pi," vol. 05, pp. 5-12, 2015.

[8] P. Sistem et al., "Journal Speed - Sentra Penelitian Engineering dan Edukasi - Volume 4 No 1 - 2012 - ijns.org," vol 4, no. 1, pp. 63-72, 2012.

[9] L. Indraswari, M. Muchlas, and W. S. Aji, "Desain Sistem Pewaktu Setelan Banyak Berbasis Mikrokontroler Avr Atmega32," TELKOMNIKA (Telecommunication Comput. Electron. Control., vol. 5, no. 1, p. 67, 2007, doi: 10.12928/telkomnika.v5i1.1343.

[10] T. H. Kusmanto and A. Susano, "PERANCANGAN SISTEM PENJADWALAN BEL SEKOLAH MENGGUNAKAN ARDUINO UNO ATMEGA328P PADA SMK,” vol. 2, 2019.

[11] A. Linarta and N. Nurhadi, "Aplikasi Bel Sekolah Otomatis Berbasis Arduino Dilengkapi Dengan Output Suara," I N F O R M a T I K a, vol. 10, no. 2, p. 1, 2019, doi: 10.36723/juri.v10i2.108.

[12] A. Giyartono and E. Kresnha, "Aplikasi Android Pengendali Lampu Rumah Berbasis Mikrokontroler Atmega328," Semin. Nas. Sains dan Teknol., no. November, pp. 1-9, 2015. 